\title{
Weight, height, and relative-reliability indicators as a management tool for reducing age at first breeding and calving of dairy heifers
}

\author{
M. Duplessis,${ }^{* 1}$ R. I. Cue,$\dagger^{2}$ D. E. Santschi, $¥$ D. M. Lefebvre, $\ddagger$ and R. Lacroix $\ddagger$ \\ *Département des Sciences Animales, Université Laval, Québec, G1V 0A6, Canada \\ †Department of Animal Science, McGill University, Ste-Anne-de-Bellevue, Québec, H9X 3V9, Canada \\ ¥Valacta, Ste-Anne-de-Bellevue, Québec, H9X 3R4, Canada
}

\section{ABSTRACT}

In Québec first calving occurs on average at 27 mo, whereas the target is 23 to 24.5 mo to maximize herd profitability. The aim of this study was to quantify current and future heifer growth using individual heifer random regressions and to generate indicators (such as heifer weight and height at 15 and $24 \mathrm{mo}$, average daily gain before and after $15 \mathrm{mo}$, age at which optimal weight for breeding is attained, i.e., $55 \%$ of mature weight, and reliability of the 15- and 24-mo weight predictions) that could be used as a practical on-farm tool. Dairy heifer weight estimated by heart girth circumference and height measured at the withers (from 0 to $27 \mathrm{mo}$ ) were obtained from the Valacta database (DHI agency, Ste-Anne-de-Bellevue, QC, Canada) from 1995 to 2012. Indicators were calculated based on the current situation of Holstein (HO), Ayrshire (AY), Jersey (JE), and Brown Swiss (BS) heifer growth in Québec. Heifers with less than 2 records were excluded from the analysis. Mature weights were determined by weight at calving of cows from third or greater lactation for a given breed and were $710 \mathrm{~kg}$ for $\mathrm{HO}, 625 \mathrm{~kg}$ for $\mathrm{AY}, 470 \mathrm{~kg}$ for JE, and $670 \mathrm{~kg}$ for BS. Estimated weights at 15 and 24 mo were 425 and 627, 334 and 482, 297 and 429, and 379 and $560 \mathrm{~kg}$ for HO, AY, JE, and BS, respectively, which are heavy enough for breeding and calving, except for AY. Relative reliabilities of the 15- and 24-mo weight predictions were on average 89 and $60 \%$, respectively, based on measurements up to 15 mo. For HO, AY, JE, and BS, wither heights at 15 and 24 mo were 134 and 143, 125 and 134, 122 and 131, and 130 and $140 \mathrm{~cm}$, respectively. Age at optimal breeding weight was $13.6,15.5,12.6$, and 14.5 mo for HO, AY, JE, and BS, respectively. These data suggest that it is realistic to expect a first calving at $24 \mathrm{mo}$ for $\mathrm{HO}, \mathrm{JE}$, and BS. A growth delay was observed for AY;

Received April 24, 2014

Accepted November 26, 2014.

${ }^{1}$ Current address: Valacta, Ste-Anne-de-Bellevue, Québec, H9X 3R4, Canada.

${ }^{2}$ Corresponding author: Roger.Cue@McGill.ca average daily gain was 655 and $538 \mathrm{~g} / \mathrm{d}$ before and after 15 mo, respectively. The average daily gain before and after 15 mo was 848 and $747 \mathrm{~g} / \mathrm{d}$ for HO, 603 and 486 $\mathrm{g} / \mathrm{d}$ for JE, and 775 and $662 \mathrm{~g} / \mathrm{d}$ for BS, respectively. These indicators could be calculated for an individual heifer and on a herd-level basis and used on farm as a management tool for reducing age at first breeding and at first calving.

Key words: heifer growth, age at first breeding, age at first calving

\section{INTRODUCTION}

Moore et al. (1991) reported that, on average, age at first calving for Holstein (HO) heifers in Québec was 28.2 mo, whereas 26.5 mo was reported 15 yr later by Pietersma et al. (2006). Despite the slight decrease in the 1990s, age at first calving has not declined over the past 10 yr in Québec, Canada, and is still higher than the recommendation of 23 to 24.5 mo to maximize farm profitability (Ettema and Santos, 2004; Pellerin and Gilbert, 2008). A similar trend in the United States was observed; average age at first calving for $\mathrm{HO}$ heifers was 26.9 mo between 1980 and 2004 (Hare et al., 2006), which represents a decrease of 1.3 mo compared with results reported by Nieuwhof et al. (1989) between 1966 and 1986. Using field data from Québec, Pietersma et al. (2006) showed that, at $14 \mathrm{mo}$, HO and Ayrshire (AY) heifers were large enough to be bred because 59 and $56 \%$ of mature $\mathrm{BW}$ were already attained at this age, respectively. According to the NRC (2001), the first breeding can occur when $55 \%$ of mature $\mathrm{BW}$ is reached. These data suggest that it is possible to achieve a first calving at 24 mo. However, in 2013 average age at first calving was still higher than the recommendation and was 27 mo in Québec for HO heifers (Valacta, 2013). Three assumptions can be proposed to explain the delay at which age at first calving occurs: (1) suboptimal ADG; (2) delayed breedings; and (3) underestimation of heifer weight at which first breeding should occur, and hence projected weight at calving.

Using mixed-model methodologies and random regressions, Cue et al. (2012) have developed a model 
allowing prediction of future growth curves of each individual heifer based upon the weight and height measurements of each heifer, which are updated thereafter as new measurements are available. These authors concluded that age at first calving in Québec above the recommended value could be explained by dairy producers not having accurate tools to predict individual heifer weight at first calving and then preferring to wait 2 or 3 mo for first breeding to ensure that heifers would be large enough at calving (Cue et al., 2012).

This study was undertaken to create an on-farm practical tool to quantify current and future growth of HO, AY, Jersey (JE), and Brown Swiss (BS) heifers using a predicting model based on random regressions as developed by Cue et al. (2012). To do so, the work of Cue et al. (2012) was extended to report on the current situation of heifer growth in Québec. From the model, indicators were generated, based on observations of the heifer (such as heifer weight and height at 15 and 24 mo, ADG before and after 15 mo, age at which optimal weight for breeding is attained, and relative reliabilities of the 15- and 24-mo weight predictions) that dairy producers could use to aid management decisions about heifer reproduction. Moreover, this study provides a portrait of the current state of heifer growth in Québec for the most popular breeds (i.e., HO, AY, $\mathrm{JE}$, and BS). It is expected that the adoption of this on-farm tool by dairy producers and specialists in Québec would increase the number of dairy-heifer growth measurements, allow better prediction of individual heifer growth, reduce age at first calving, and thereby improve farm profitability.

\section{MATERIALS AND METHODS}

\section{Data Collection}

Weight, estimated by heart girth circumference, and wither-height data of dairy heifers (from 0 to $27 \mathrm{mo}$ ) were obtained from the Valacta database (DHI agency, Ste-Anne-de-Bellevue, QC, Canada) from 1995 to 2012. The same data set used by Pietersma et al. (2006) and Cue et al. (2012) formed part of this study and was updated to take into account measurements from 2006 to 2012. A complete description of data recording and extraction from the Valacta database was given previously (Pietersma et al., 2006; Cue et al., 2012). Briefly, estimated BW and height records were measured by Valacta technicians in dairy farms participating in the heifer recording option. Body weight was estimated using calibrated weight tapes measuring heart girth circumference. Because electronic scales are not commonly available on Québec dairy farms, estimated BW using a tape is a practical and reliable technique (Heinrichs et al., 1992). For HO, AY, JE, and BS heifers, a total of $401,474,20,668,3,226$, and 3,563 estimated BW records and $359,650,18,066,2,796$, and 3,416 wither-height records were collected, respectively.

Mature BW was estimated from Valacta BW records of multiparous cows from the 4 studied breeds (i.e., HO, AY, BS, and JE) from 2007 to 2012. Random regressions were used with a linear model based on a Wilmink function on DIM to estimate average BW at calving (Wilmink, 1987). Mature BW represents the average estimated weight at calving for multiparous cows from third, fourth, and fifth lactations within each breed.

\section{Data Verification}

This study was carried out in 2 steps: step one was an update of estimates of equation parameters for $\mathrm{HO}$, AY, and BS breeds of the study of Cue et al. (2012) and an initial estimation of the same parameters (for weight and height) for JE heifers. The second step was an examination of the population growth curves and various indicators that might be used to monitor and assist in improving heifer growth and achieving recommended age at first calving.

Table 1. Numbers of animals and records, before and after editing, for weight (step one)

\begin{tabular}{|c|c|c|c|c|}
\hline Item & Holstein & Ayrshire & Jersey & $\begin{array}{l}\text { Brown } \\
\text { Swiss }\end{array}$ \\
\hline Number of animals, before & 147,024 & 7,475 & 1,788 & 1,464 \\
\hline Records, initially & 401,474 & 20,668 & 3,226 & 3,563 \\
\hline Number of animals & 145,828 & 7,439 & 1,766 & 1,457 \\
\hline Records & 399,437 & 20,589 & 3,188 & 3,555 \\
\hline \multicolumn{5}{|c|}{$\begin{array}{l}\text { After imposing the requirement of age at first observation }<5 \text { and }>19 \text { mo } \\
\text { for the last observation }\end{array}$} \\
\hline Records & 91,665 & 4,746 & 892 & 1,497 \\
\hline \multicolumn{5}{|c|}{ After imposing the requirement of $4+$ records per heifer } \\
\hline Number of animals & 11,269 & 515 & 165 & 317 \\
\hline Records & 87,844 & 4,592 & 892 & 1,497 \\
\hline
\end{tabular}


Table 2. Numbers of animals and records, before and after editing, for height (step one)

\begin{tabular}{|c|c|c|c|c|}
\hline Item & Holstein & Ayrshire & Jersey & $\begin{array}{c}\text { Brown } \\
\text { Swiss }\end{array}$ \\
\hline Number of animals, before & 131,312 & 6,861 & 1,585 & 1,396 \\
\hline Records, initially & 359,650 & 18,066 & 2,796 & 3,416 \\
\hline Number of animals & 130,370 & 6,789 & 1,467 & 1,323 \\
\hline Records & 356,194 & 17,962 & 2,635 & 3,324 \\
\hline \multicolumn{5}{|c|}{$\begin{array}{l}\text { After imposing the requirement of age at first observation }<5 \text { and }>19 \text { mo } \\
\text { for the last observation }\end{array}$} \\
\hline Records & 86,105 & 3,784 & 616 & 236 \\
\hline \multicolumn{5}{|c|}{ After imposing the requirement of $4+$ records per heifer } \\
\hline Number of animals & 10,654 & 422 & 91 & 27 \\
\hline Records & 82,407 & 3,624 & 604 & 230 \\
\hline
\end{tabular}

Given the fact that data records were obtained from nonedited on-farm measurements, editing to remove any data-entry mistakes was required; see Cue et al. (2012) for examples of calves recorded as weighing $900 \mathrm{~kg}$ at 2 mo of age. Tables 1 and 2 present numbers of animals and records before and after editing, for parameter estimation for weight and height, respectively. For step one, initial estimates, based on Cue et al. (2012), were used to compute the expected weight and height for a given age. Individual observations from the raw data set more than 4 standard deviations from the expected weight or height for age were removed. This procedure was iterated upon until no more observations were removed. Heifers having less than 4 measurements and having their first measurement after $5 \mathrm{mo}$, or their last one before 19 mo, were removed from the data set for estimation of equation parameters. Fixed-effects regression estimates and random-effects variance-covariance components were then estimated, as explained below (sections: Curve Modeling for Weight and Height).

For the second step of the study, looking at the population heifer growth curves, the same basic datavalidation approach was used, using the estimated parameters, fixed effects, and variance components, to remove outliers. The predicted growth curves (using the estimated parameters from the first step of this study) for each heifer that had at least 2 measurements (for weight or height) were calculated using the approach outlined in Cue et al. (2012). Tables 3 and 4 present the numbers of records before and after editing, to remove invalid records, and to impose the requirement of at least 2 records per animal, up to either 15 or 24 mo.

\section{Data Analysis and Calculations}

Curve Modeling for Weight. Weight data records were analyzed as described by Cue et al. (2012). Briefly, weight data were analyzed using $\mathrm{R}$ (version 1.15.2) package nlme. The statistical model fitted linear and quadratic fixed-effect regressions on age (in mo) as well as intercept, linear, and quadratic random regressions for each animal, and a residual variance modeled as a power function of the expected weight for age, power of the mean. The statistical model for each of the 4 breeds was

$$
\begin{aligned}
& Y_{i j}=a_{0}+a_{1} \times \operatorname{age}_{i j}+a_{2} \times \operatorname{age}_{i j}^{2} \\
& +b_{0 i}+b_{1 i} \times \operatorname{age}_{i j}+b_{2 i} \times \operatorname{age}_{i j}^{2}+e_{i j},
\end{aligned}
$$

where $Y_{i j}$ is the weight of the $i$ th animal at the $j$ th age (in mo); $a_{0}$ is the overall, fixed-effect population inter-

Table 3. Numbers of animals and records by 15 and 24 mo, for weight (step two)

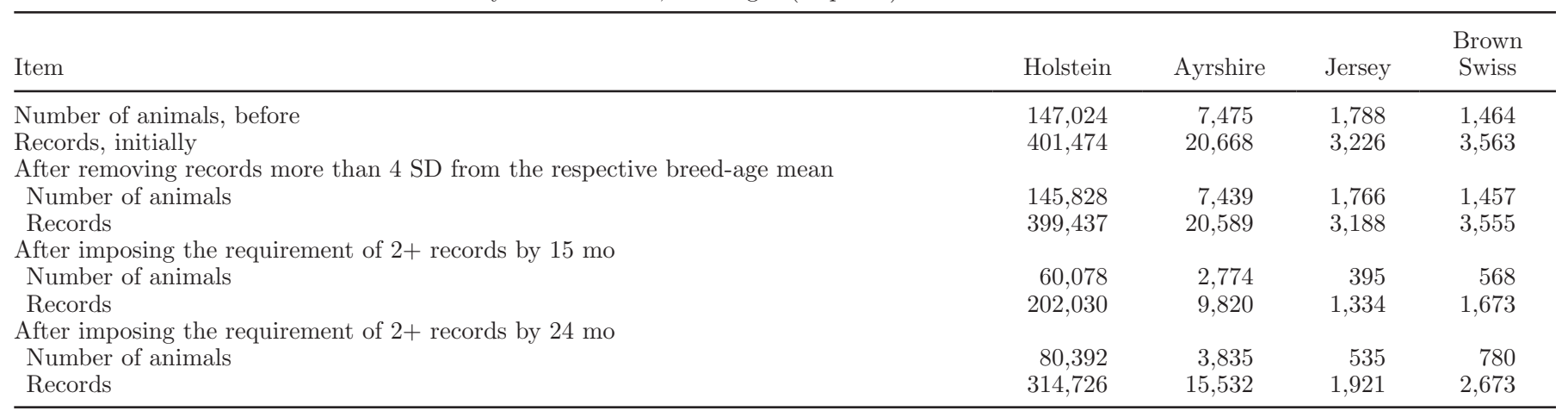


Table 4. Numbers of animals and records by 15 and 24 mo, for height (step two)

\begin{tabular}{|c|c|c|c|c|}
\hline Item & Holstein & Ayrshire & Jersey & $\begin{array}{c}\text { Brown } \\
\text { Swiss }\end{array}$ \\
\hline Number of animals, before & 131,312 & 6,861 & 1,585 & 1,396 \\
\hline Records, initially & 359,650 & 18,066 & 2,796 & 3,416 \\
\hline Number of animals & 130,370 & 6,789 & 1,467 & 1,323 \\
\hline Records & 356,194 & 17,962 & 2,635 & 3,324 \\
\hline \multicolumn{5}{|c|}{ After imposing the requirement of $2+$ records by $15 \mathrm{mo}$} \\
\hline \multicolumn{5}{|c|}{ After imposing the requirement of $2+$ records by 24 mo } \\
\hline Number of animals & 73,007 & 3,418 & 409 & 727 \\
\hline Records & 283,633 & 13,584 & 1,555 & 2,546 \\
\hline
\end{tabular}

cept; $a_{1}$ is the overall, fixed-effect population average coefficient of regression of weight on age; $a_{2}$ is the overall, fixed-effect population average regression coefficient of weight on age ${ }^{2}, b_{0 i}$ is the random intercept specific to the $i$ th animal, $b_{0 i} \sim \mathrm{N}\left(0, \sigma_{b_{0}}^{2}\right)$, where $\sigma_{b_{0}}^{2}$ is the variance of random intercepts; $b_{1 i}$ is the random coefficient of regression of weight on age for the $i$ th animal, $b_{1 i} \sim \mathrm{N}\left(0, \sigma_{b_{1}}^{2}\right)$, where $\sigma_{b_{1}}^{2}$ is the variance of random linear regression coefficients; $b_{2 i}$ is the random coefficient of regression of weight on age $^{2}$ for the $i$ th animal, $b_{2 i} \sim \mathrm{N}\left(0, \sigma_{b_{2}}^{2}\right)$, where $\sigma_{b_{2}}^{2}$ is the variance of random quadratic regression coefficients; $e_{i j}$ is the random residual error associated with the $j$ th weight measurement on the ith animal, and $e_{i j} \sim \mathrm{N}\left(0, \sigma_{e \mid \text { age }}^{2}\right), \quad$ where $\sigma_{e \text { lage }}^{2}=\sigma^{2}|X b|^{\mathrm{POM}}, \mathrm{POM}$ is power of the mean, and $X b$

Table 5. Parameters estimates for weight and height curves for the 4 breeds of dairy heifers

\begin{tabular}{|c|c|c|c|c|}
\hline Item $^{1}$ & Holstein & Ayrshire & Jersey & Brown Swiss \\
\hline \multicolumn{5}{|l|}{ Weight } \\
\hline$b_{0}$ & 35.3511 & 35.6775 & 18.5384 & 35.9895 \\
\hline$b_{1}$ & 28.1419 & 22.1374 & 21.0152 & 24.6821 \\
\hline$b_{2}$ & -0.14580 & 0.14787 & -0.16287 & -0.11938 \\
\hline$\sigma_{b_{0}}^{2}$ & 113.099 & 100.718 & 66.6634 & 0.04650 \\
\hline$\sigma_{b_{0} b_{1}}$ & -23.217 & -14.540 & -9.372 & -0.8383 \\
\hline$\sigma_{b_{1}}^{2}$ & 20.2547 & 15.5009 & 19.823 & 15.1148 \\
\hline$\sigma_{b_{0} b_{2}}$ & 0.81313 & 0.37549 & 0.37719 & -0.01950 \\
\hline$\sigma_{b_{1} b_{2}}$ & -0.65941 & -0.29665 & -0.58952 & -0.35155 \\
\hline$\sigma_{b_{2}}^{2}$ & 0.03090 & 0.01485 & 0.02231 & 0.01216 \\
\hline$\sigma_{e}^{2}$ & 0.31463 & 0.24908 & 19.2556 & 0.93358 \\
\hline POM & 1.2298 & 1.2638 & 0.4101 & 1.0022 \\
\hline \multicolumn{5}{|l|}{ Height } \\
\hline$A$ & 148.972 & 139.424 & 136.784 & 146.975 \\
\hline$b$ & 0.4862 & 0.4646 & 0.4727 & 0.4740 \\
\hline$k$ & 0.1039 & 0.1014 & 0.1001 & 0.0957 \\
\hline$\sigma_{A}^{2}$ & 25.966 & 40.113 & 25.086 & 12.467 \\
\hline$\sigma_{A b}$ & 0.0167 & 0.0682 & -0.0668 & 0.0447 \\
\hline$\sigma_{b}^{2}$ & 0.0006886 & 0.001428 & 0.0007259 & 0.0005995 \\
\hline$\sigma_{A k}$ & -0.05570 & -0.09515 & -0.09993 & -0.004942 \\
\hline$\sigma_{b k}$ & -0.0002872 & 0.000116 & 0.00006280 & -0.0002064 \\
\hline$\sigma_{k}^{2}$ & 0.0003067 & 0.0004693 & 0.0005845 & 0.0000855 \\
\hline$\sigma_{e}^{2}$ & 4.4975 & 4.9715 & 4.0071 & 3.2699 \\
\hline
\end{tabular}

${ }^{1} b_{0}=$ intercept; $b_{1}=$ linear regression coefficient; $b_{2}=$ quadratic regression coefficient; $\sigma=$ the appropriate variance or covariance of corresponding random terms $\left(\sigma_{b_{0}}^{2}=\right.$ variance of the random intercepts for weight, $\sigma_{\mathrm{Ab}}$ $=$ covariance between $A$, the random effect for mature height, and $b$, the random effect pertaining to initial birth height, and so on); POM = power of the mean; $A=$ mature height of the animal; $b=$ parameter meaning that the equation does not go through the origin at time zero; that is, at heifer birth in the present case; $k=$ parameter that influences the rate of maturing. 

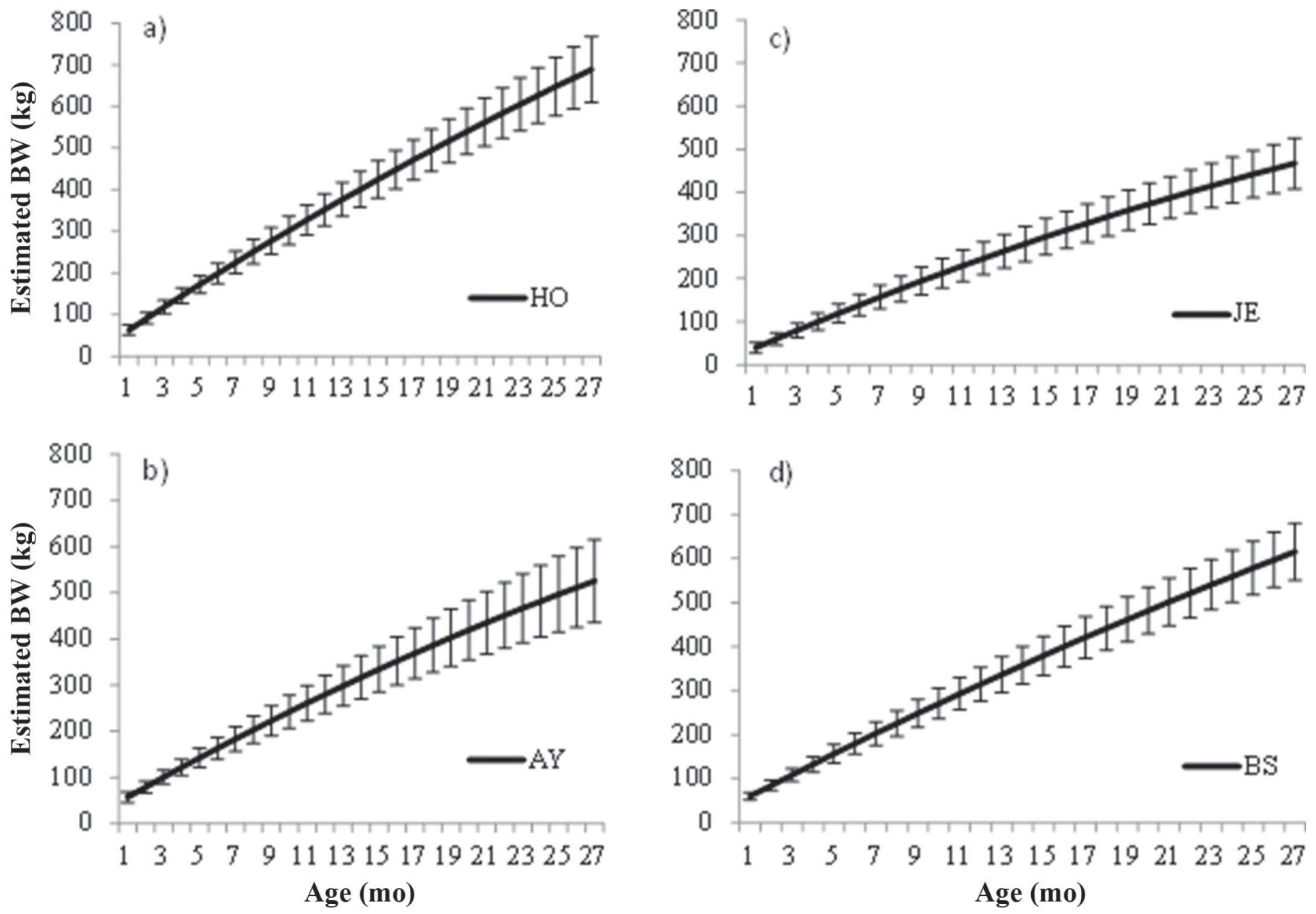

Figure 1. Estimated BW and standard deviation measured by heart girth circumference using calibrated tapes during heifer growth for Holstein (a; HO), Ayrshire (b; AY), Jersey (c; JE), and Brown Swiss (d; BS).

corresponds to the expected value for each observation. Parameter estimates are presented in Table 5.

Curve Modeling for Height. As for weight data, height data records were analyzed as described by Cue et al. (2012) using a nonlinear random regression model. Briefly, height data were analyzed using $\mathrm{R}$ and the nlme package according to the Brody/monomolecular equation $\left[A\left(1-b e^{-k t}\right)\right]$ with random regression effects for $A, b$, and $k$ for each animal, and $t=$ age (in mo). In the Brody equation, $A$ represents the mature height of the animal and $b$ is a parameter meaning that the equation does not go through the origin at time zero; that is, at heifer birth in the present case. The parameter $k$ influences the rate of maturing. The statistical model for each of the 4 breeds was

$$
h_{i j}=\left(A+A_{i}\right)\left[1-\left(b+b_{i}\right) \times e^{\left(-\left(k+k_{i}\right)_{j}\right)}\right]+e_{i j},
$$

where $h_{i j}$ is the height of the $i$ th animal at the $j$ th age (in mo) and $A_{i}, b_{i}$, and $k_{i}$ are the random effects corre- sponding to the fixed effects $A, b$, and $k$, for the $i$ th animal. The residual variance $\left(\sigma_{\varepsilon}^{2}\right)$ was tested to see if a constant variance was appropriate, or whether a residual variance as a function of the expected height or age was more appropriate; a constant variance provided the best-fitting model. Parameter estimates are presented in Table 5.

Indicator Calculations. Six indicators for each breed were computed from the second-step edited data set, that is to say the valid data, with a requirement of 2 or more records per heifer: (1) estimated weight at 15 and $24 \mathrm{mo}$; (2) estimated height at 15 and 24 mo; (3) ADG before and after 15 mo; (4) age at which optimal weight for breeding is attained, i.e., $55 \%$ of mature weight (NRC, 2001); (5) relative reliability of the 15-mo weight prediction; and (6) relative reliability of the 24-mo weight prediction. Indicators of weight and height at 15 and 24 mo were calculated from respective curve parameter estimates. Average daily gain before and after 15 mo was obtained from the first derivative 
Table 6. Indicators calculated from 1995 to 2012 records

\begin{tabular}{|c|c|c|c|c|c|c|c|c|}
\hline Indicator & \multicolumn{2}{|c|}{ Holstein } & \multicolumn{2}{|c|}{ Ayrshire } & \multicolumn{2}{|c|}{ Jersey } & \multicolumn{2}{|c|}{ Brown Swiss } \\
\hline Mature weight $(\mathrm{kg})$ & 710 & 65 & 625 & 64 & 470 & 64 & 670 & 61 \\
\hline Weight at $15 \mathrm{mo}(\mathrm{kg})$ & 425 & 34 & 334 & 29 & 297 & 26 & 379 & 36 \\
\hline Weight at $24 \mathrm{mo}(\mathrm{kg})$ & 627 & 39 & 482 & 48 & 429 & 27 & 560 & 43 \\
\hline Height at $15 \mathrm{mo}(\mathrm{cm})$ & 134.0 & 4.8 & 125.0 & 7.0 & 122.0 & 4.0 & 130.0 & 5.3 \\
\hline Before $15 \mathrm{mo}$ & 848 & 76 & 655 & 66 & 603 & 57 & 775 & 79 \\
\hline After 15 mo & 747 & 40 & 538 & 82 & 486 & 25 & 662 & 32 \\
\hline Age at optimal breeding weight (mo) & 13.6 & 1.4 & 15.5 & 1.4 & 12.6 & 1.4 & 14.5 & 1.7 \\
\hline \multicolumn{9}{|l|}{ Relative reliabilities obtained from data before $15 \mathrm{mo}$} \\
\hline Relative reliability for 15 -mo weight prediction (\%) & 87 & 15 & 90 & 14 & 92 & 12 & 87 & 13 \\
\hline Relative reliability for 24-mo weight prediction (\%) & 43 & 14 & 69 & 14 & 60 & 11 & 67 & 14 \\
\hline \multicolumn{9}{|l|}{ Relative reliabilities obtained from data before $24 \mathrm{mo}$} \\
\hline
\end{tabular}

${ }^{1}$ Based on $55 \%$ of mature weight according to NRC (2001).
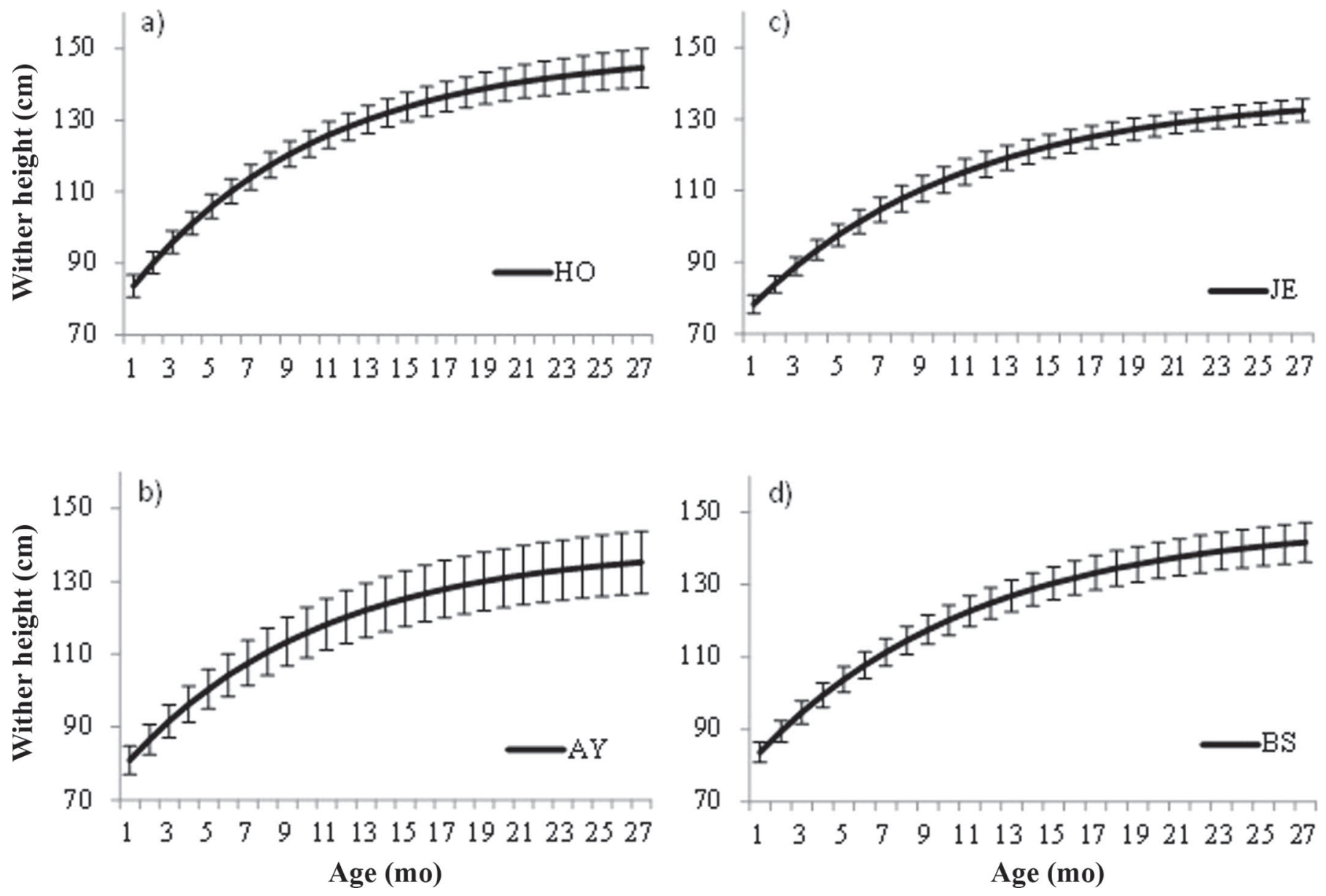

Figure 2. Estimate wither height and standard deviation during heifer growth for Holstein (a; HO), Ayrshire (b; AY), Jersey (c; JE), and Brown Swiss (d; BS). 


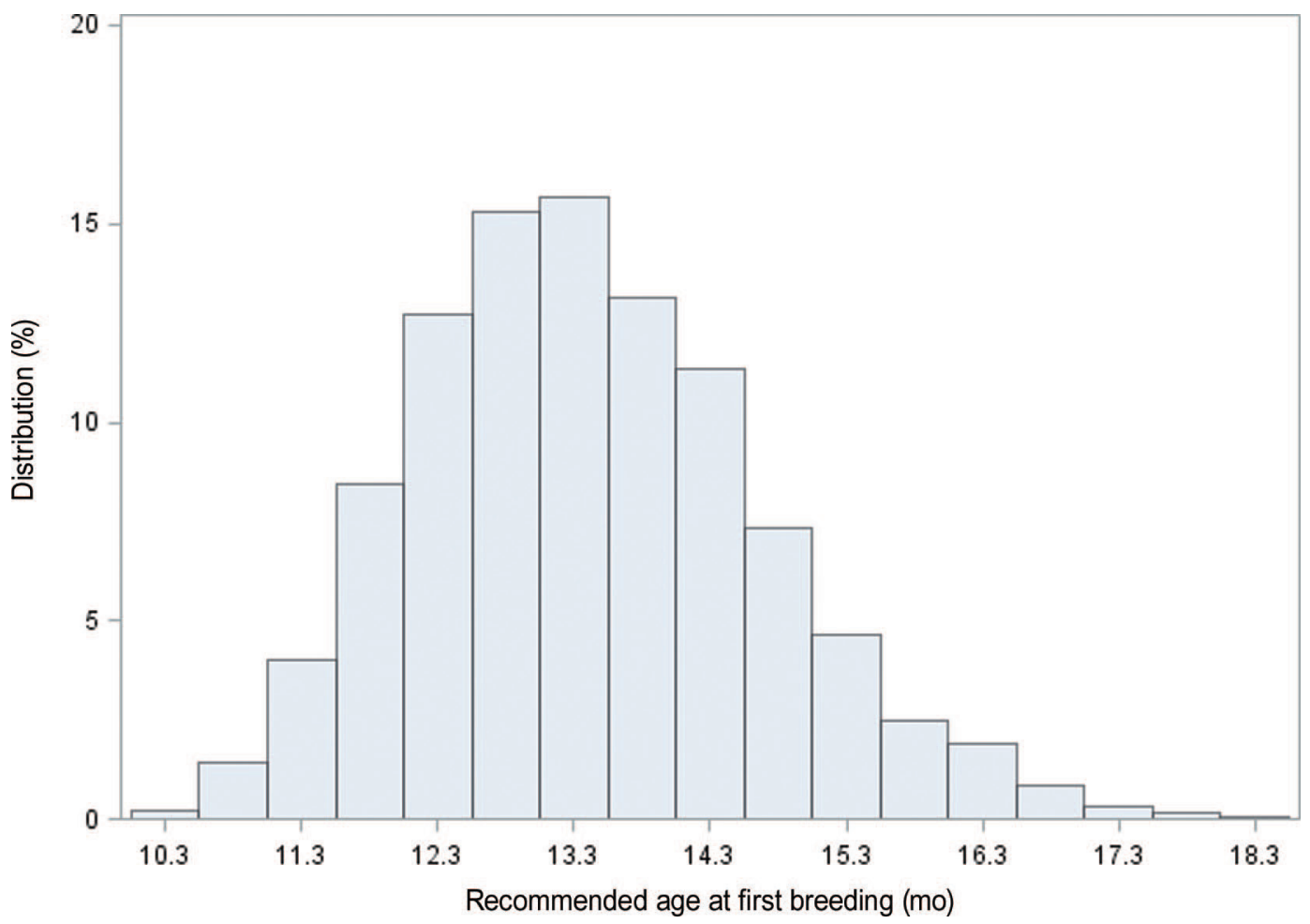

Figure 3. Histogram of the recommended optimum age at first breeding (mo) for Holstein heifers raised in Québec, from 1995 to 2012 . Color version available online.

of the weight quadratic equation. Age at which optimal weight for breeding is attained was calculated from the roots of the weight quadratic equation, using $55 \%$ of breed-average mature weight (NRC, 2001). Relative reliability of the 15- and 24-mo weight prediction was calculated as the prediction error variance, relative to that expected to be obtained when a heifer was measured routinely every $3 \mathrm{mo}$, starting at $2 \mathrm{mo}$ of age, i.e., at $2,5,8,11$, and 14 mo of age for measurements that could be taken before a heifer is large enough to be first bred and at 2, 5, 8, 11, 14, 17, 20, and 23 mo for continuing measurements to monitor growth to calving. Three-monthly recording was chosen as a baseline because it was initially thought that this was likely to provide a reasonable monitoring of growth without requiring excessively repetitive measuring.

\section{RESULTS AND DISCUSSION}

Estimated BW growth curves by random regression using population-parameter estimates for $\mathrm{HO}, \mathrm{AY}$, JE, and BS heifers, as well and the estimated standard deviation, by month of age are presented in Figure 1 . As expected, HO was the heaviest breed throughout growth, followed by BS, AY, and JE. The same trend was observed for height growth curves (Figure 2). Ma- ture weight, optimal weight at first breeding, as well as indicator results are shown in Table 6. Most experiments studying heifer growth were carried out on HO heifers and to a lesser extent, on JE heifers; studies reporting growth data on AY and BS heifers are scarce.

Mature weights reported in this study are higher than those from Van Amburgh et al. (1998) and NRC (2001), mainly due to Canadian genetic, environmental, and management changes. Selection for milk production has led to a correlated response in BW (Berry et al., 2003; Oltenacu and Broom, 2010). A recent report by Sewalem et al. (2014) presented a genetic trend of $+0.75 \mathrm{~kg} / \mathrm{yr}$, and a phenotypic trend of $+1.83 \mathrm{~kg} / \mathrm{yr}$, in Québec HO, and Cue (2010) reported an estimated genetic trend of $+0.45 \mathrm{~kg} / \mathrm{yr}$ for cow BW in Québec AY. Annual reports of Valacta over the last 15 yr show a trend for increased cow and heifer BW. The average whole-herd BW for HO was $596 \mathrm{~kg}$ in 1998 and was 654 $\mathrm{kg}$ in 2012 (Valacta, 2013). Notwithstanding that this is a raw, unadjusted average and does not take into account the proportion of heifers in a herd, nor the DIM when the estimated cow BW was recorded (mostly at the first test day after calving), cow BW has steadily increased (approximately $3.8 \mathrm{~kg} / \mathrm{yr}$ ) in $\mathrm{HO}$, and a similar picture for the other breeds is observed. Likewise, the raw, unadjusted heifer BW (normally recorded at 


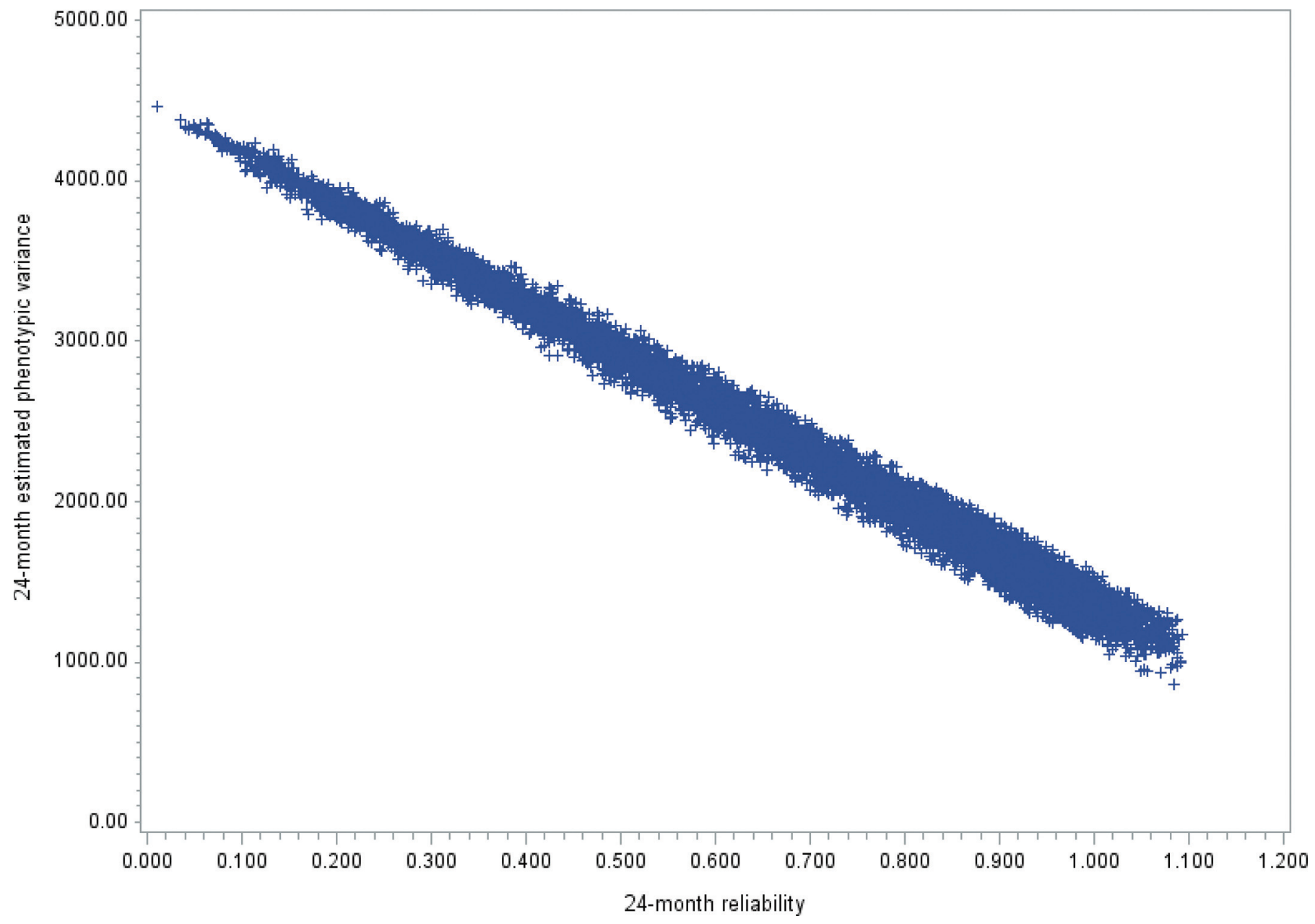

Figure 4. Estimated 24-mo phenotypic variance as a function of the 24-mo relative reliability (based on measurements up to 24 mo of age). Color version available online.

the first test-day after calving) in primiparous $\mathrm{HO}$ cows has increased from $559 \mathrm{~kg}$ in 1998 to $612 \mathrm{~kg}$ in 2012 (Valacta, 2013).

Weight and height at 15 and 24 mo for $\mathrm{HO}$ and JE reported in the current study are higher by about $70 \mathrm{~kg}$ and $10 \mathrm{~cm}$ as compared with data from Pennsylvania and New York heifers (Heinrichs and Hargrove, 1987; 1991), caused in part by the above-mentioned genetic change (Sewalem et al., 2014). This will have implications in terms of growth rates that can be expected and required, and it illustrates the need for continuing recording and monitoring to ensure that advice to producers remains appropriate; larger and heavier cows will translate into larger and heavier heifers. What is interesting and useful are not only the simple population descriptions of the various breed averages, but also the magnitude of the variability. For the 15-mo estimated BW (which would correspond to the approximate age when heifers would likely be bred) the standard devia- tions were between 26 and $36 \mathrm{~kg}$ (Table 6). Likewise, for 24-mo BW, the standard deviations of the predicted values were between 27 and $48 \mathrm{~kg}$. Both of these values indicate substantial variability among heifers.

In a meta-analysis studying the effect of prepubertal ADG on first-lactation production, Zanton and Heinrichs (2005) concluded that an ADG of $800 \mathrm{~g} / \mathrm{d}$ for HO heifers could maximize total milk and protein yield. However, the work of Zanton and Heinrichs is hard to reconcile because they did not account for the mature weight of animals, and hence, it is not easy to relate their recommendation of ADG with these results. Although puberty is reached before $15 \mathrm{mo}$, ADG before $15 \mathrm{mo}$ of age in the present study is higher by $48 \mathrm{~g} / \mathrm{d}$ than is recommended for HO heifers.

Perhaps the most interesting indicator for dairy producers is age at optimal breeding weight. As stated by Cue et al. (2012), heifers are actually large enough to be bred at 14 to $15 \mathrm{mo}$ of age and to calve at $24 \mathrm{mo}$, but 


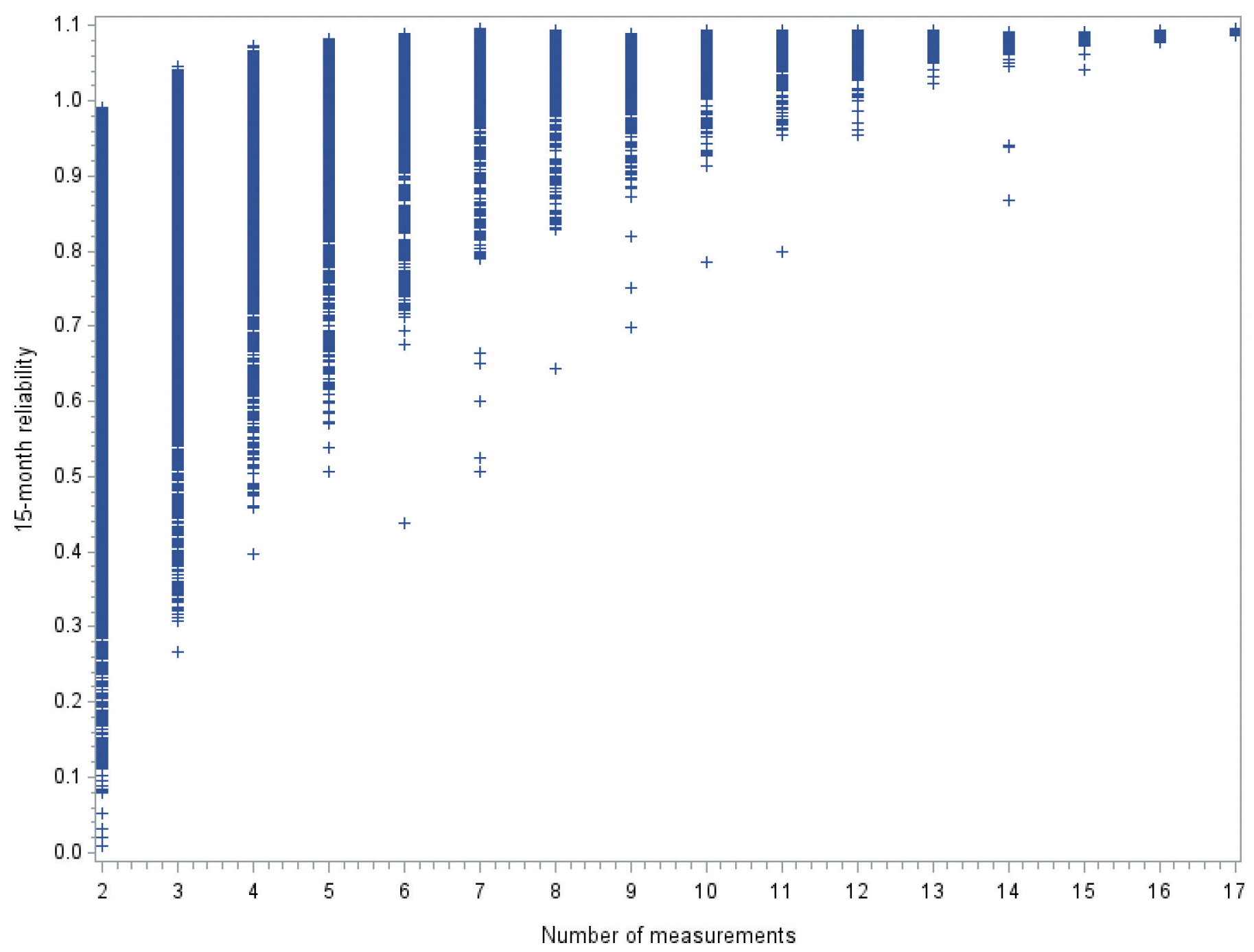

Figure 5. Relationship between the number of measurements on a Holstein heifer and its relative reliability. Color version available online.

dairy producers have had no way to estimate the age at which heifer BW is optimal for first breeding and to predict the BW at $24 \mathrm{mo}$ and thus, presumably, prefer to wait 2 or 3 mo to be confident that their heifers will be mature enough. Using $55 \%$ of mature weight as a target, age at optimal breeding weight was attained at $13.6 \pm 1.4,15.5 \pm 1.4,12.6 \pm 1.4$, and $14.5 \pm 1.7$ for $\mathrm{HO}, \mathrm{AY}, \mathrm{JE}$, and BS, respectively. Table 6 shows that optimal weight at first breeding, i.e., $55 \%$ of breed average mature weight, was attained before $15 \mathrm{mo}$ as weight at this age was higher than optimal weight at first breeding, except for AY. Figure 3 presents the distribution of recommended optimum age at first breeding (for HO); it can be seen that by 15 mo of age, $90 \%$ of heifers are large enough to be bred. Pietersma et al. (2006) reported that the number of breedings per conception in Québec was 1.29 for $\mathrm{HO}$ and 1.31 for AY. These data, combined with the fact that estimated BW at 24 mo was higher than $82 \%$ of mature weight as recommended by NRC (2001), suggest that it is realistic to aim for a first calving at $24 \mathrm{mo}$ for HO. The same recommendation could be made for JE and BS. At 24 mo, HO heifers had reached on average $88 \%$ of mature weight, whereas JE and BS heifers had attained 91 and $84 \%$ of mature weight, respectively. On the other hand, $77 \%$ of mature weight was reached at 24 mo for AY heifers, which is insufficient (NRC, 2001). Nevertheless, records collected from 2007 to 2012 for AY heifers show that age at first breeding was 14.3 mo and that $84 \%$ of mature weight was reached at 24 mo. This increase is mainly due to an improvement of ADG by 58 and $52 \mathrm{~g} / \mathrm{d}$ before and after $15 \mathrm{mo}$, respectively. A question that arises is whether there are possible influences of milk or animal marketing forces that could act on age at first calving. It could be hypothesized that producers might deliberately follow a somewhat seasonal 
pattern of age at first calving, perhaps to increase the number of heifers calving in later summer or early fall. This would in all likelihood result in delayed breeding to result in a larger number of heifers calving in late summer or early fall, without necessarily increasing heifer weight. To address this issue the average age at first calving, by month of calving, was examined; the monthly least squares means of age at first calving varied little, from 26.5 to 27.8 mo. In Quebec the quota production-management system basically requires individual producers to deliver one-twelfth of their annual quota in each month, thus the number of calvings has to remain fairly stable throughout the year. Depending upon the actual production in the province, then, if there is a shortfall in the autumn, producers may be allocated 1 or 2 extra days of production. For example, the provincial producers' federation (responsible for collective milk marketing) may decide in mid-August that the overall production is slightly below expectation and hence that they will allow each producer, during the month of October, to ship 32/31 of their monthly allocation. Because these decisions are not foreseeable and are only decided upon a couple of months ahead, they are most unlikely to be able to have any effect on either age or weight at first calving. By the time such and extra allocation is made, any heifer is already bred and hence its age at calving is immutable.

The presented tables and discussion deliberately excluded any effects of herd or year of birth. Including the effect of year in the model explained only between 0.5 and $0.7 \%$ of the sums of squares for each trait (15mo weight, 24-mo weight, age at recommended first breeding). Herd was deliberately excluded from the model; the prediction model, as outline in Cue et al. (2012), is a phenotypic prediction model not specific to any individual herd. The objective of this study was to provide a useable portrait of heifer growth. If we had included year or herd as an effect in our presented descriptive results, then the results would only be applicable within year of birth, herd, or both, which would rather negate the utility. A wide range of optimal ages at first breeding are presented; some of which would have heifers calving for the first time 4 to 5 mo beyond a 24-mo target age at calving. Certainly, recommendations of optimal age at first calving would be higher in herds that experienced poor early heifer growth. Should that herd breed heifers at older ages, or improve heifer growth rates? That will depend upon the producer; what we can suggest is that it is quite possible, for all 4 breeds, to obtain growth rates such that heifers can calve at 24 mo of age.

The relative reliabilities of the prediction of $15-$ mo BW, from measurements up to $15 \mathrm{mo}$, averaged 87 to 92\% (Table 6), with the standard deviations of these relative reliabilities being 12 to $14 \%$. The prediction of 24-mo BW from measurements up to 15 mo had, obviously, lower average relative reliabilities, 43 to $69 \%$. When heifers were measured up until 24 mo, the average relative reliabilities ranged from 67 to $82 \%$. The estimated phenotypic variance showed a linear decline with increasing relative reliability; see Figure 4 for the plot of estimated 24-mo phenotypic variance against the 24-mo relative reliability (for HO). Figure 5 shows the relationship observed between reliability and number of observations; it depends upon the pattern of just when the observations on a heifer are taken. A heifer with 2 weight measurements taken shortly after weaning will obtain a very low relative reliability for 15-mo predicted weight, whereas a heifer, also with 2 measurements, but these taken shortly before 15 mo may have a relative reliability approaching one. It can be seen that the relative reliability did not exceed 1.1, even for those animals with monthly measurements; some producers do record individual heifer weight and height each month. The change in the estimated phenotypic variance when the relative reliability goes from 1.0 (corresponding to 3 -monthly recording) to 1.1 is quite small. It would therefore indicate that recording routinely at 3-monthly intervals (about 8 measurements per heifer, evenly spread throughout growth to first calving of the heifer) provides a sufficiently good description and prediction of the growth and that more frequent recording may not be economically justifiable nor necessary. The approach outlined here can be used to predict and monitor the growth curve of individual heifers and hence groups of animals. It should be noted that this is all predicated on measuring (weight and height) heifers in a producer's herd on a routine and continuous basis.

\section{CONCLUSIONS}

This study aimed to describe the current state of heifer growth in Québec for the most numerous breeds (i.e., HO, AY, JE, and BS) between 1995 and 2012. As compared with previous studies, mature weight, estimated weight measured by heart girth circumference, and wither height at 15 and 24 mo were higher in the present study, in part due to genetic gain. For HO, JE, and BS breeds, the age at which optimal breeding weight is attained allows targeting of a first calving at 23.5 to $24 \mathrm{mo}$, as recommended to maximize herd profitability. On the other hand, a growth delay was observed on AY heifers; a first calving at about 25.5 mo could be expected. The AY growth delay was ruled out from 2007 to 2012 by improving ADG and allowed first calving at the recommended age. This study presented indicators that could be calculated on a herd basis or 
for each heifer within a herd and be used as a management tool to decrease age at first calving in dairy herds.

\section{ACKNOWLEDGMENTS}

We acknowledge the help of Raphael Jedar and Christian Koenig. This work was funded by the Ministère de l'Agriculture, des Pêcheries et de l'Alimentation (Québec) and Agriculture and Agri-Food Canada under the Growing Forward framework agreement Programme de soutien à l'innovation en agroalimentaire. We thank two anonymous referees whose suggestions have improved the manuscript.

\section{REFERENCES}

Berry, D. P., F. Buckley, P. Dillon, R. D. Evans, M. Rath, and R. F. Veerkamp. 2003. Genetic relationships among body condition score, body weight, milk yield, and fertility in dairy cows. J. Dairy Sci. 86:2193-2204.

Cue, R. I. 2010. Genetic correlations amongst body weight, fat yield, protein yield and body condition score in Ayrshire cows. 9th World Congr. Genet. Appl. Livest. Prod., Leipzig, Germany. German Society for Animal Science, Neustadt, Germany.

Cue, R. I., D. Pietersma, D. Lefebvre, R. Lacroix, K. Wade, D. Pellerin, A.-M. de Passillé, and J. Rushen. 2012. Growth modeling of dairy heifers in Québec based on random regression. Can. J. Anim. Sci. 92:33-47.

Ettema, J. F., and J. E. P. Santos. 2004. Impact of age at calving on lactation, reproduction, health, and income in first-parity Holsteins on commercial farms. J. Dairy Sci. 87:2730-2742.

Hare, E., H. D. Norman, and J. R. Wright. 2006. Trends in calving ages and calving intervals for dairy cattle breeds in the United States. J. Dairy Sci. 89:365-370.

Heinrichs, A. J., and G. L. Hargrove. 1987. Standards of weight and height for Holstein heifers. J. Dairy Sci. 70:653-660.

Heinrichs, A. J., and G. L. Hargrove. 1991. Standards of weight and height for Guernsey and Jersey heifers. J. Dairy Sci. 74:16841689 .
Heinrichs, A. J., G. W. Rogers, and J. B. Cooper. 1992. Predicting body weight and wither height in Holstein heifers using body measurements. J. Dairy Sci. 75:3576-3581.

Moore, R. K., B. W. Kennedy, L. R. Schaeffer, and J. E. Moxley. 1991. Relationships between age and body weight at calving and production in first lactation Ayrshires and Holsteins. J. Dairy Sci. $74: 269-278$.

NRC. 2001. Nutrient Requirements of Dairy Cattle. 7th rev. ed. National Academy Press, Washington, DC.

Nieuwhof, G. J., R. L. Powell, and H. D. Norman. 1989. Ages at calving and calving intervals for dairy cattle in the United States. J. Dairy Sci. 72:685-692.

Oltenacu, P. A., and D. M. Broom. 2010. The impact of genetic selection for increased milk yield on the welfare of dairy cows. Anim. Welf. 19:39-49.

Pellerin, D., and D. Gilbert. 2008. La gestion des coûts de remplacement. Pages 33-44 in Les Bovins Laitiers. Centre de Référence en Agriculture et Agroalimentaire du Québec (CRAAQ), Québec, $\mathrm{QC}$, Canada.

Pietersma, D., R. Lacroix, D. Lefebvre, R. Cue, and K. M. Wade. 2006. Trends in growth and age at first calving for Holstein and Ayrshire heifers in Quebec. Can. J. Anim. Sci. 86:325-336.

Sewalem, A., R. I. Cue, K. Wade, H. Delgado, R. Lacroix, D. Lefebvre, J. Dubuc, and E. Bouchard. 2014. Body weight and its association with other traits of economic importance in Canadian dairy cows. Accessed Feb. 23, 2014. http://cgil.uoguelph.ca/dcbgc/ Agenda1402/DCBGC\%20BWT_Sewalem_February.pdf.

Valacta. 2013. Votre expertise, moi j'en profite! L'évolution de la production laitière québécoise 2012. Le producteur de lait québécois. Valacta, Ste-Anne-de-Bellevue, Québec, Canada.

Van Amburgh, M. E., D. G. Fox, D. M. Galton, D. E. Bauman, and L. E. Chase. 1998. Evaluation of National Research Council and Cornell Net Carbohydrate and Protein Systems for predicting requirements of Holstein heifers. J. Dairy Sci. 81:509-526.

Wilmink, J. B. M. 1987. Adjustment of test-day milk, fat and protein yield for age, season and stage of lactation. Livest. Prod. Sci. $16: 335-348$.

Zanton, G. I., and A. J. Heinrichs. 2005. Meta-analysis to assess effect of prepubertal average daily gain of Holstein heifers on firstlactation production. J. Dairy Sci. 88:3860-3867. 